\title{
Factors that influence the incidence of breast cancer in Arica, Chile (Review)
}

\author{
GLORIA M. CALAF ${ }^{1,5}$, FRESIA CABA ${ }^{2}$, JORGE FARIAS ${ }^{3}$ and FRANCISCO ROTHHAMMER ${ }^{1,4}$ \\ ${ }^{1}$ Instituto de Alta Investigación, ${ }^{2}$ Facultad de Ciencias de la Salud, Universidad de Tarapacá, Arica; ${ }^{3}$ Instituto de Biotecnología \\ de Tarapacá, Universidad Arturo Prat, Iquique; ${ }^{4}$ Instituto de Ciencias Biomédicas, Facultad de Medicina, Universidad \\ de Chile, Santiago, Chile; ${ }^{5}$ Center for Radiological Research, Columbia University Medical Center, New York, NY, USA
}

Received December 15, 2009; Accepted April 23, 2010

DOI: 10.3892/ol_00000103

\begin{abstract}
Breast cancer is a common disease estimated to occur in 1 in 9 women over their lifetime. Epidemiological research has identified a number of risk factors for breast cancer. Racial and ethnic differences in breast cancer mortality rates have been difficult to ascertain. The present review reports that there was an increase in the incidence of breast cancer in Arica, Chile, from 1997 to 2007, particularly in 2005, reaching $55.1 \%$ per 100,000 women, while the percentage decreased in 2006 and 2007. A greater percentage of breast cancer was found in individuals between 46 and 65 years of age when the population was distributed by age. The Indian population, Aymara, had only a $13.9 \%$ incidence of the disease. The incidence for breast cancer for patients with no family background reached approximately $88 \%$, with or without Indian ethnicity, and $98.4 \%$ of these women did not have prior hormonal therapy. When the stage of the disease and the number of pregnancies were considered, results showed that there was an increase in the progression of the disease from stage I to stage III in women that had 1-3 pregnancies. Results also showed that 20.9 and $33.2 \%$ who received prior tamoxifen treatment were in stages I and IIA, respectively. The breast cancer incidence reached $42.4 \%$ when patients had a sister with the disease. It can be concluded that important differences in the risk factors of breast cancer should be identified in the future for a comparison with other biological factors, such as genetic and molecular factors. This may provide greater insight into breast cancer aetiology in different populations.
\end{abstract}

\section{Contents}

1. Risk factors of breast cancer

2. Cancer biomarkers

Correspondence to: Dr Gloria M. Calaf, Instituto de Alta Investigación, Universidad de Tarapacá, Calle Antofagasta \#1520, Arica 8097877, Chile

E-mail: gmc24@columbia.edu

Key words: breast cancer, hormonal replacement, family history
3. Hormonal replacement therapy

4. Breast cancer and family history

5. Results and conclusions

\section{Risk factors of breast cancer}

Breast cancer is a common disease estimated to occur in 1 in 9 women over their lifetime. Thus, a large population is available for epidemiological, genetic and molecular studies. The aetiology of human breast cancer is unknown; however, it is a complex disease, characterized by a progressive multistep process caused by interactions of both genetic and non-genetic factors.

Epidemiological research has identified a number of risk factors for breast cancer. However, racial and ethnic differences in breast cancer mortality rates have been difficult to ascertain (1). Possible explanations include differences in the biological characteristics of the tumor (2), patient characteristics such as obesity that may affect prognosis, frequency of mammography examinations (3), timeliness and completeness of breast cancer diagnosis and treatment $(4,5)$, social factors such as education, literacy and cultural beliefs, and economic factors (6-8).

Age is the strongest demographic risk factor for most human malignancies, including breast cancer (9). Approximately $80 \%$ of all breast cancers occur in women $>50$ years of age; the 10-year probability of developing invasive breast cancer increases from $\sim 1.5 \%$ at age 40 , to $\sim 3 \%$ at age 50 and to $\sim 4 \%$ by the age of 70 , resulting in a cumulative lifetime risk of $13.2 \%$ ( 1 in 8 ) and a near 9-fold higher incidence rate in women $>50$ years of age as compared to their younger counterparts (10). Fig. 1A shows the increase in the incidence of breast cancer in Arica, Chile, from 1997 to 2007, particularly in 2005 , reaching $55.1 \%$ per 100,000 women. This percentage decreased in 2006 and 2007, but was higher than the previous years. Fig. 1B shows the distribution of patients by age in relation to the incidence of breast cancer. A greater percentage, reaching $25.6 \%$, was noted among individuals between 46 and 65 years of age. The Indian population, Aymara, showed only a $13.9 \%$ incidence as noted in Fig. 1C. Fig. 1D shows that the incidence of breast cancer in patients with no family history was $\sim 88 \%$, with or without Indian background. 


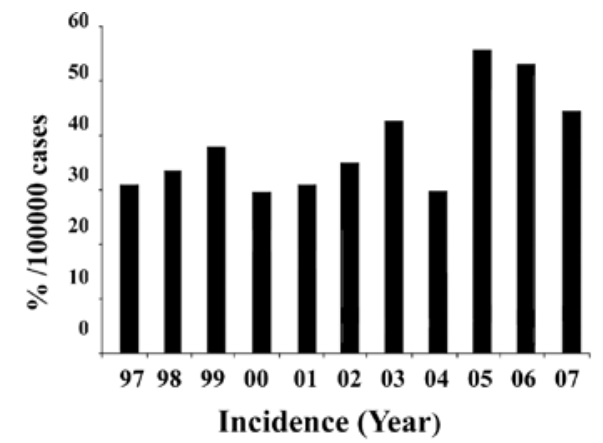

C

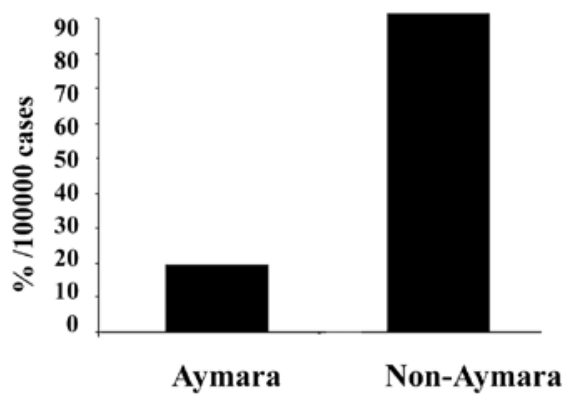

B

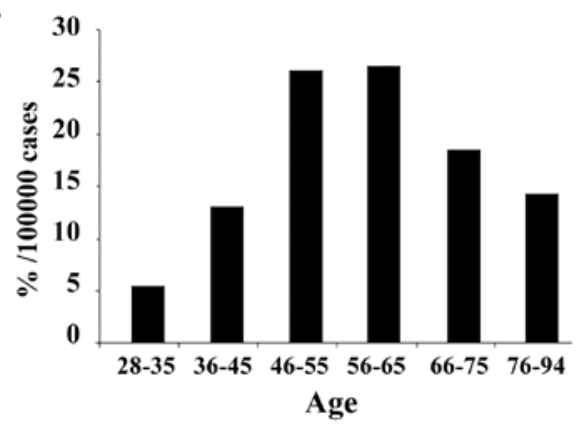

D

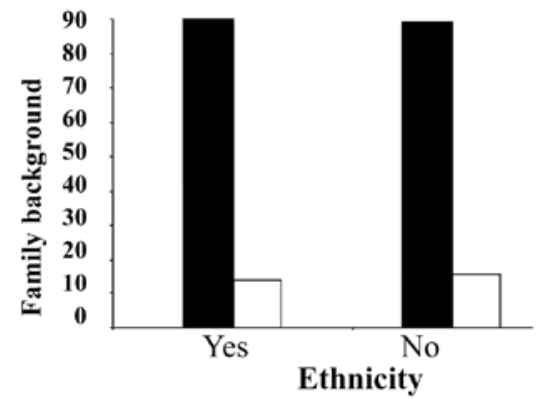

Figure 1. Breast cancer in Arica, Chile, in relation to incidence (percentage per 100,000 cases) per year [years 1997 (97) to 2007 (07)] (A); age (percentage per 100,000 cases) (B); ethnicity, Aymara and non-Aymara (percentage per 100,000 cases) (C) and ethnicity and family background (percentage per 100,000 cases) (D).

\section{Cancer biomarkers}

Tumor biology is altered with aging, and at the cellular level it has been linked to increased genomic instability, global and promoter-specific epigenetic changes and altered expression of genes involved in cell division and extracellular matrix remodelling (11-16). A number of associations have led to the hypothesis that cancer in older individuals results from cumulative mutations, increased epigenetic gene silencing, telomere dysfunction and altered estromal milieu (17). Younger age at diagnosis ( $\leq 45$ years of age) is associated with more aggressive breast cancer biomarkers, including overexpression of the ERBB2 growth factor receptor (18), abnormal p53 expression (19), estrogen receptor (ER) negativity (18-20), higher nuclear grade and higher Ki-67 proliferation index $(19,20)$.

Even though breast cancer biomarkers are interdependent, ER expression in particular, is inversely correlated with abnormal p53 (19), overexpression of ERBB2 (19), a high $\mathrm{Ki}-67$ and nuclear grade and poor prognosis (21). In general, the normal mammary gland ER content as well as the proportion of ER-expressing (ER-positive) in ductal epithelial cells increase with each decade of age and reach a plateau with menopause at age $\sim 50$ years $(22,23)$. By contrast, breast cancer ER expression continues to increase beyond menopause, reaching an $\sim 25$-fold difference between normal and malignant mammary gland ER expression by the age 70 years (22). Notably, the expression of certain ER-inducible gene markers, such as progesterone receptor (PR), pS2, Bcl2 and cathepsin D, do not show any significant relationship with age at diagnosis $(18,22)$, while other markers show an increased expression in breast cancers arising earlier in life (24).

Of importance is the age-related change in PR co-expression within ER-positive breast cancers, since PR has been used extensively as a clinical indicator for a functioning ER pathway in tumors likely to respond to endocrine therapy (25). Among all ethnic patient groups, ER-positive/PR-negative breast cancers showed the greatest age-related increase in incidence after the age of 40 (26). Potentially relevant to this ER-positive/PR-negative phenotype is the fact that growthfactor-activated pathways down-regulate PR expression (26) and that the inverse correlation between overexpression of the ERBB2 growth factor receptor and positive PR is only noted in breast cancers arising after the age of 40 (27). The ageadjusted breast cancer incidence rates for women of racial/ ethnic minority groups are substantially lower than those for Caucasian women. In addition, African-American women are likely to be diagnosed at a more advanced stage (28) and to have larger tumors, usually ER-negative $(29,30)$ and of high grade (29), than those found in Caucasian women. AfricanAmerican women also have higher breast cancer mortality (31). On the other hand, the association of oral contraceptives with risk of breast cancer was similar in Hispanic and non-Hispanic white women in certain studies (32). AfricanAmerican (33,34), Hispanic $(33,35)$, native American $(35,36)$, Hawaiian and Filippino $(33,37,38)$ women living in the US are more likely to be diagnosed with advanced stages of breast cancer and to have poorer survival after diagnosis compared to non-Hispanic white women. Alternatively, Japanese and Chinese women exhibit no difference with respect to breast cancer stage and survival (33), they also present less advanced stages and have better survival when compared to non-Hispanic whites $(37,38)$.

Differences in socio-demographic, cultural and behavioral characteristics have been postulated. Stage and survival differences may also be related to the differential expression of breast tumor characteristics that have been independently 
A

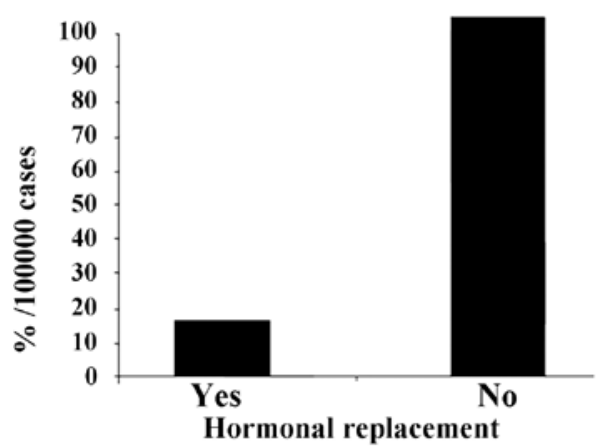

C

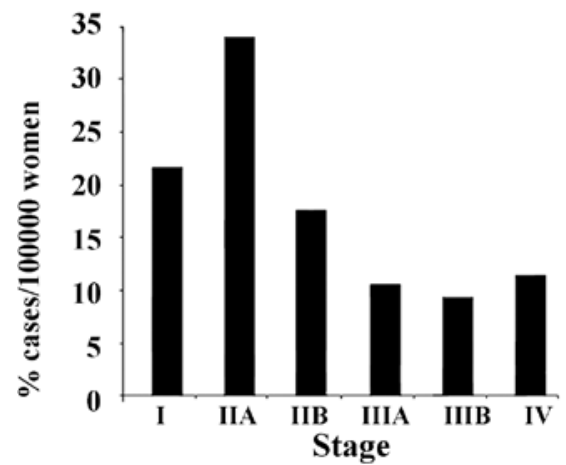

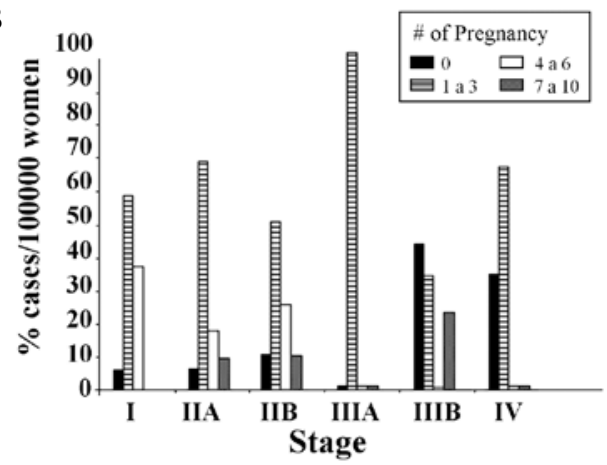

D

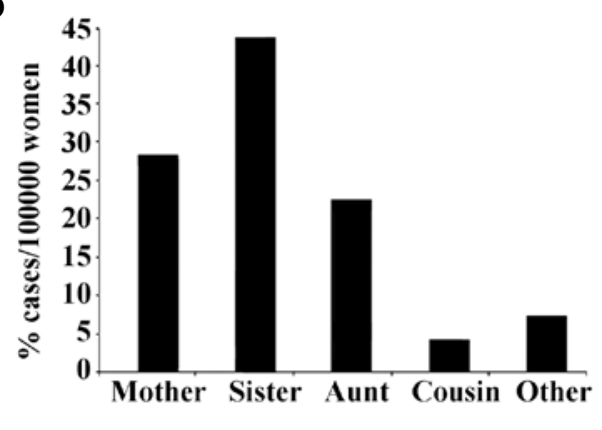

Figure 2. Breast cancer in Arica, Chile from 1997 to 2007 (percentage per 100,000 cases) in relation to hormonal replacement (A), stage of the disease and number of pregnancies (B), stage of the disease in relation to tamoxifen treatment (C) and family history (D).

shown to be related to mortality. Specifically, hormone receptor-negative breast tumors (39) are associated with poorer survival, whereas those tumors that have a lobular histology are associated with better survival (40). Previous studies suggested that African-American women are more likely to have ER-negative, PR-negative (41) and medullary (42) breast tumors. One study found that Asian women were more likely to have ER-/PR-negative breast tumors than non-Hispanic white women (43). African-American and Hispanic white women appear to have decreased risks of lobular carcinoma and increased risks of medullary carcinoma compared to nonHispanic whites $(41,42,44)$. A more pronounced expression of cell cycle- and proliferation-associated genes has emerged as a strong defining feature of ER-positive breast cancers arising in younger women, perhaps even leading to the earlier clinical appearance. This observation is consistent with the more aggressive clinical nature of early-age-onset breast cancer.

\section{Hormonal replacement therapy}

The use of hormone replacement therapy is associated with an increased risk of lobular tumors (45). Breast cancer incidence rates rose throughout the 1980s and 1990s in the US and declined during 2004. This decline was attributed to the reduction in menopausal hormone use (46). However, data gathered from 1995 to 2004 did not consider either the histological type or race/ethnicity which may have influenced these trends.

Invasive ductal carcinoma and invasive lobular carcinoma incidence rates fell steadily from 1998 to 2004. Declines in overall breast cancer rates and invasive ductal carcinoma were limited to women who were 50 years of age, non-Hispanic white and Asian/Pacific Islanders, and declines in the rates of invasive lobular carcinoma were primarily limited to non-Hispanic white women. Fig. 2A shows the incidence of breast cancer in Arica, Chile, from 1997 to 2007, in relation to hormonal replacement. Of these women, $98.4 \%$ did not have such treatment.

Fig. 2B shows the incidence during the same years in relation to stage of the disease and number of pregnancies. Results showed an increase in the progression of the disease that reached $100 \%$ from stage I to stage III in women that had 1-3 pregnancies. Reports (47) have confirmed that women of childbearing age experience an increased breast cancer risk associated with a completed pregnancy. For younger women, the increase in breast cancer risk was transient, and within a decade after parturition a crossover effect resulted in an ultimate protective benefit. The post-partum peak of increased risk was greater in women with advanced maternal age. Furthermore, their lifetime risk for developing breast cancer remained elevated for a number of years, with the crossover to protection occurring decades later or not at all.

Fig. $2 \mathrm{C}$ indicates that 20.9 and $33.2 \%$ of the breast cancer patients who received tamoxifen treatment were in stages I and IIA, respectively. Fig. 2D shows the incidence of breast cancer in Arica, Chile, in relation to family history, with the results indicating that the incidence of breast cancer reached $42.4 \%$ when the patient had a sister with the disease.

\section{Breast cancer and family history}

Ethnic variation in the incidence rate of breast cancer is considerable. Non-Hispanic white women, women of various races/ ethnicities living in the US, including African-Americans, 
native Americans, Filippinos, Chinese, Koreans, Vietnamese, Indians/Pakistanis, Mexicans, South/Central Americans and Puerto Ricans, were found to have a greater risk of presenting with breast cancer with characteristics associated with a poor prognosis. A combination of biological, genetic, environmental and lifestyle differences across these populations is likely to account for these variations. One of the strongest risk factors for breast cancer is a family history of the disease (48), although this factor varies among ethnic groups. In general, ethnicity has been equated with minority status. Thus, studies on the topic are evaluations of incidence, mortality and survival of black people, Asians (primarily Chinese, Japanese and Filipino), Hispanics, American Indians, native Hawaiians and Alaska natives. Migrant studies (49) have demonstrated that variability in incidence is attributed to differences in risk factor levels. Similarly, geographic variation within a country may also be partly influenced by population risk factor differences (50).

Breast cancer risk is also influenced by host differences in the genetic variation or predisposition to the disease. Such risk has been attributed to ethnic variation in the frequency of specific susceptibility genes. A combination of BRCA1 and BRCA2 gene mutations appears to be responsible for 20-30\% of the cases with familial breast cancer. The prevalence of BRCA1/2 pathogenic mutations largely varies within different populations; in particular, the rate of mutations in breast and/ or ovarian cancer families of Italian origin is controversial and ranges from 8 to $37 \%$. A number of major genes that confer an increased susceptibility to breast cancer when inherited in a mutated form have been identified (51). Studies have suggested that the relative proportion of breast/ovarian cancer families with mutations in BRCA1 or BRCA2 varies in different populations. For example, the percentage of familial breast/ovarian cancer explained by BRCA1 mutations is estimated to be $29 \%$ in Italy, $21 \%$ in Britain and 9\% in Iceland (52). In addition, in the majority of populations, BRCA1 mutations are more common than their BRCA2 counterparts in breast/ovarian cancer families, although in Iceland BRCA2 mutations are more common than BRCA1 ones (52). Specific mutations identified in BRCA1 or BRCA2 also differ by ethnic group. In Israel, three specific mutations were reported to account for $36 \%$ of familial breast/ovarian cancer (53). A specific BRCA1 mutation, 185delAG, was observed primarily in the Ashkenazi Jewish population (54).

Since specific mutations appear to confer different breast cancer risks, the variation in breast cancer risk in different populations may be attributed, in part, to underlying differences in genetic and molecular factors $(55,56)$. These genetic differences may appear as ethnic-specific differences in breast cancer risk associated with a family history of the disease. Diet patterns and breast cancer risk in Hispanic and non-Hispanic white women indicate that the rates of breast cancer (57) and obesity (58) differ among ethnic groups. The rate of breast cancer among Hispanic women is $2 / 3$ of the rate noted among non-Hispanic white women (57), while the rate of obesity is higher among Hispanic women (58). An increase in the prevalence of obesity with higher intakes of animal protein and fat composition has previously been shown in non-Hispanic white women, but not in Hispanic control participants (59). Ethnic differences were noted in the association of obesity with risk for breast cancer in postmenopausal Hispanic and
non-Hispanic white women. However, no differences were noted in these same associations in pre-menopausal women (60). Fig. 2D shows the percentage per 100,000 women with a breast cancer family history. The data indicated that breast cancer reached $42.4 \%$ for individuals who had a sister with a history of cancer.

\section{Results and conclusions}

The present review reports an increase in the incidence of breast cancer in Arica, Chile, from 1997 to 2007. A greater percentage of breast cancer was found in individuals between 46 and 65 years of age when the population was distributed by age. The Aymara group had only a $13.9 \%$ incidence of the disease. The incidence of breast cancer in patients with no family background reached approximately $88 \%$, either with or without Indian ethnicity. There was an increase in the progression of the disease from stage I to stage III in women that had 1-3 pregnancies, and 20.9 and $33.2 \%$ who had received tamoxifen treatment were in stages I and IIA, respectively. The incidence of breast cancer reached $42.4 \%$ when the patient had a sister with the disease. Therefore, it can be concluded that important differences in breast cancer risk factors should be identified in the future for comparison with other biological factors such as genetic and molecular factors. This may provide greater insight into breast cancer aetiology in different populations.

\section{Acknowledgements}

Thanks are given to FONDECYT 1080482 (G.M.C.) and to the Convenio de Desempeño Universidad de Tarapacá-Mineduc (G.M.C., F.R.). The secretarial assistance of Danissa Barahona is also greatly appreciated.

\section{References}

1. Breen N, Kessler LG and Brown ML: Breast cancer control among the underserved - an overview. Breast Cancer Res Treat 40: 105-115, 1996.

2. Elledge RM, Clark GM, Chamness GC and Osborne CK: Tumor biologic factors and breast cancer prognosis among white, Hispanic and black women in the United States. J Natl Cancer Inst 86: 705-712, 1994.

3. Burns RB, McCarthy EP, Freund KM, Marwill SL, Shwartz M, Ash A and Moskiwitz MA: Black women receive less mammography even with similar use of primary care. Ann Intern Med 125: 173-182, 1996.

4. Chang SW, Kerlikowske K, Napoles-Springer A, Posner SF, Sickles EA and Perez-Stable EJ: Racial differences in timeliness of follow-up after abnormal screening mammography. Cancer 78: 1395-1402, 1996

5. Facione NC: Delay versus help seeking for breast cancer symptoms: a critical review of the literature on patient and provider delay. Soc Sci Med 36: 1521-1534, 1993.

6. Gordon NH, Crowe JP, Brumberg DJ and Berger NA: Socioeconomic factors and race in breast cancer recurrence and survival. Am J Epidemiol 135: 609-618, 1992.

7. Singh GK, Miller BA and Hankey BF: Changing area socioeconomic patterns in US cancer mortality, 1950-1998: part II - lung and colorectal cancers. J Natl Cancer Inst 94: 916-925, 2002.

8. Wells BL and Horm JW: Stage at diagnosis in breast cancer: race and socioeconomic factors. Am J Public Health 82: 1383-1385, 1992.

9. Edwards B, Howe HL, Ries L, Thun M, Rosenberg H, Wingo P, Jemal A and Feigal E: Annual report to the nation on the status of cancer, 1973-1999, featuring implications of age and aging on US cancer burden. Cancer 94: 2766-2792, 2000. 
10. Smigal C, Jemal A, Ward E, Cokkinides V, Smith R, Howe HL and Thun $\mathrm{M}$ : Trends in breast cancer by race and ethnicity: update 2006. CA Cancer J Clin 56: 168-183, 2006.

11. Benz CC, Campisi J, Cohen HJ, Ershler WB, Haubein L and Irminger-Finger I: Meeting report: translational research at the aging and cancer interface. Cancer Res 67: 4560-4563, 2007.

12. Geigl JB, Langer S, Barwisch S, Pfleghaar K, Lederer G and Speicher MR: Analysis of gene expression patterns and chromosomal changes associated with aging. Cancer Res 64: 8550-8557, 2004.

13. Issa JP: Aging, DNA methylation and cancer. Crit Rev Oncol Hematol 32: 31-43, 1999.

14. Richardson B: Impact of aging on DNA methylation. Ageing Res Rev 2: 245-261, 2003.

15. Ershler WB and Longo DL: Aging and cancer: issues of basic and clinical science. J Natl Cancer Inst 89: 1489-1497, 1997.

16. Balducci L and Ershler WB: Cancer and ageing: a nexus at several levels. Nat Rev Cancer 5: 655-662, 2005.

17. DePinho RA: The age of cancer. Nature 408: 248-254, 2000.

18. Eppenberger-Castori S, Moore DH Jr, Thor AD, Edgerton SM Kueng W, Eppenberger $U$ and Benz CC: Age-associated biomarker profiles of human breast cancer. Int J Biochem Cell Biol 34: 1318-1330, 2002.

19. Rudolph P, Olsson H, Bonatz G, Ratjen V, Bolte H, Baldetorp B Fernö M, Parwaresch R and Alm P: Correlation between p53, c-erbB-2, and topoisomerase IIa expression, DNA ploidy, hormonal receptor status and proliferation in 356 node-negative breast carcinomas: prognostic implications. J Pathol 187: 207-216, 1999.

20. Rapiti E, Fioretta G, Verkooijen HM, Vlastos G, Schafer P, Sappino AP, Kurtz J, Neyroud-Caspar I and Bouchardy C: Survival of young and older breast cancer patients in Geneva from 1990 to 2001. Eur J Cancer 41: 1446-1452, 2005.

21. Harvey JM, Clark GM, Osborne CK and Allred DC: Estrogen receptor status by immunohistochemistry is superior to the ligand binding assay for predicting response to adjuvant endocrine therapy in breast cancer. J Clin Oncol 17: 1474-1481, 1999.

22. Quong J, Eppenberger-Castori S, Moore D III, Scott GK, Birrer MJ, Kueng W, Eppenberger $U$ and Benz CC: Age-dependent changes in breast cancer hormone receptor and oxidant stress markers. Breast Cancer Res Treat 76: 221-236, 2002.

23. Shoker BS, Jarvis C, Sibson DR, Walker C and Sloane JP Oestrogen receptor expression in the normal and pre-cancerous breast. J Pathol 188: 237-244, 1999.

24. Creighton C, Cordero K, Larios J, Miller R, Johnson M, Chinnaiyan A, Lippman $\mathrm{M}$ and Rae J: Genes regulated by estrogen in breast tumor cells in vitro are similarly regulated in vivo in tumor xenografts and human breast tumors. Genome Biol 7: R28, 2006.

25. Horwitz KB and McGuire WL: Estrogen control of progesterone receptor in human breast cancer. J Biol Chem 253: 2223-2228, 1978.

26. Arpino G, Weiss H, Lee AV, Schiff R, De Placido S, Osborne CK and Elledge RM: Estrogen receptor-positive, progesterone receptor-negative breast cancer: association with growth factor receptor expression and tamoxifen resistance. J Natl Cancer Inst 97: 1254-1261, 2005.

27. Huang HJ, Neven P, Drijkoningen M, et al: Association between HER-2/neu and the progesterone receptor in oestrogendependent breast cancer is age-related. Breast Cancer Res Treat 91: 81-87, 2005.

28. Ghafoor A, Jemal A, Ward E, Cokkinides V, Smith P and Thun M: Trends in breast cancer by race and ethnicity. CA Cancer J Clin 53: 342-355, 2003.

29. Li CI, Malone KE and Daling JR: Differences in breast cancer hormone receptor status and histology by race and ethnicity among women 50 years of age and older. Cancer Epidemiol Biomarkers Prev 11: 301-307, 2002.

30. Joslyn SA: Hormone receptors in breast cancer: racial differences in distribution and survival. Breast Cancer Res Treat 73 : 45-59, 2002.

31. Newman LA, Mason J, Cote D, Vin Y, Carolin K, Bouwman D and Colditz GA: African-American ethnicity, socioeconomic status and breast cancer survival: a meta-analysis of 14 studies involving over 10,000 African-American and 40,000 white American patients with carcinoma of the breast. Cancer 94 2844-2854,2002.
32. Sweeney C, Giuliano AR, Baumgartner KB, Byers T, Herrick JS, Edwards SL and Slaterry ML: Oral, injected and implanted contraceptives and breast cancer risk among US Hispanic and non-Hispanic white women. Int $\mathrm{J}$ Cancer 21: 2517-2523, 2007.

33. Hsu JL, Glaser SL and West DW: Racial/ethnic differences in breast cancer survival among San Francisco Bay Area women. J Natl Cancer Inst 89: 1311-1312, 1997.

34. Chevarley F and White E: Recent trends in breast cancer mortality among white and black US women. Am J Public Health 87: 775-781, 1997.

35. Frost F, Tollestrup K, Hunt WC, Gilliland F, Key CR and Urbina CE: Breast cancer survival among New Mexico Hispanic, American Indian and non-Hispanic white women (1973-1992). Cancer Epidemiol Biomarkers Prev 4: 861-866, 1996.

36. Sugarman JR, Dennis LK and White E: Cancer survival among American Indians in western Washington state (United States). Cancer Causes Control 5: 440-448, 1994.

37. Meng L, Maskarinec G and Lee J: Ethnicity and conditional breast cancer survival in Hawaii. J Clin Epidemiol 50: 1289-1296, 1997.

38. Meng L, Maskarinec G and Wilkens L: Ethnic differences and factors related to breast cancer survival in Hawaii. Int $\mathrm{J}$ Epidemiol 26: 1151-1158, 1997.

39. McGuire WL and Clark GM: Prognostic factors and treatment decisions in axillary-node-negative breast cancer. N Engl J Med 326: 1756-1761, 1992.

40. Du Toit RS, Locker AP, Ellis IO, Elston CW, Nicholson RI, Robertson JFR and Blamey RW: An evaluation of differences in prognosis, recurrence patterns and receptor status between invasive lobular and other invasive carcinomas of the breast. Eur J Surg Oncol 17: 251-257, 1991.

41. Gapstur SM, Dupuis J, Gann P, Collila S and Winchester DP: Hormone receptor status of breast tumors in black. Hispanic and non-Hispanic white women: an analysis of 13,239 cases. Cancer 77: 1465-1471, 1996.

42. Joslyn SA and West MM: Racial differences in breast carcinoma survival. Cancer 88: 114-123, 2000.

43. Pegoraro RJ, Karnan V, Nirmul D and Joubet SM: Estrogen and progesterone receptors in breast cancer among women of different racial groups. Cancer Res 46: 2117-2120, 1986.

44. Klonoff-Cohen HS, Schaffroth LB, Edelstein SL, Molgaard C and Saltzstein SL: Breast cancer histology in whites, African Americans, Hispanics, Asians and Pacific Islanders. Ethnicity Health 3: 189-198, 1998

45. Li CI, Weiss NS, Stanford JL and Daling JR: Hormone replacement therapy in relation to risk of lobular and ductal breast cancer in middle-aged women. Cancer 88: 2570-2577, 2000.

46. Lyons TR, Schedin PJ and Borges VFJ: Pregnancy and breast cancer: when they collide. Mammary Gland Biol Neoplasia 14: 87-98, 2009.

47. Li CI and Daling JR: Changes in breast cancer incidence rates in the United States by histology subtype and race/ethnicity, 1995 to 2004. Cancer Epidemiol Biomarkers Prev 16: 2773-2780, 2007.

48. Sellers TA: Genetic factors in the pathogenesis of breast cancer: their role and relative importance. J Nutr 127: S929-S932, 1997.

49. Thomas DB and Karagas MR: Migrant studies. In: Cancer Epidemiology and Prevention. 2nd edition. Schottenfeld D and Fraumeni JF Jr (eds). Oxford University Press, New York, pp236-254, 1996.

50. Robbins AS, Brescianini S and Kelsey JL: Regional differences in known risk factors and the higher incidence of breast cancer in San Francisco. J Natl Cancer Inst 89: 960-965, 1997.

51. Cornelisse CJ, Cornelis RS and Devilee P: Genes responsible for familiar breast cancer. Path Res Pract 192: 684-693, 1996.

52. Szabo CI and King MC: Population genetics of BRCA1 and BRCA2. Am J Hum Genet 60: 1013-1020, 1997.

53. Levy-Lahad E, Lahad A, Eisenberg S, et al: Founder BRCA1 and BRCA2 mutations in Ashkenazi Jews in Israel: frequency and differential penetrance in ovarian cancer and in breast-ovarian cancer families. Am J Hum Genet 60: 1059-1067, 1997.

54. Berman DB, Wagner-Costalas J, Schultz DC, Lynch HT, Daly M and Godwin AK: Two distinct origins of a common BRCA1 mutation in breast-ovarian cancer families: a genetic study of 15 185delAG mutation kindreds. Am J Hum Genet 58: 1166-1176, 1996. 
55. Struewing JP, Abeliovich D, Peretz T, Avishai N, Kaback MM, Collins FS and Brody LC: The carrier frequency of the BRCA1 185 delAG mutation is approximately 1 percent in Ashkenazi Jewish individuals. Nat Genet 11: 198-200, 1995

56. Gayther SA, Mazoyer WW, Russell PA, Harrington PA Mathias Chiano M and Seal S: Germline mutations of the BRCA1 gene in breast/ovarian cancer families provide evidence for a phenotype/genotype correlation. Nat Genet 11: 428-433, 1995.

57. Carrozza SE and Lowe HL: Patterns of cancer incidence among US Hispanics/Latinos, 1995-2000. Cancer Causes Control 17: 1067-1075, 2006.
58. Ogden CL, Carroll MD, Curtin LR, McDowell MA, Tabak CJ and Flegal KM: Prevalence of overweight and obesity in the United States, 1999-2004. JAMA 295: 1549-1555, 2006.

59. Murtaugh MA, Herrick JS, Sweeney C, et al: Diet composition and risk of overweight and obesity in women living in the south western United States. J Am Diet Assoc 107: 1311-1321, 2007.

60. Slattery ML, Sweeney C, Edwards S, et al: Body size, weight change, fat distribution and breast cancer risk in Hispanic and non-Hispanic white women. Breast Cancer Res Treat 38: 33-41, 2006. 